\title{
HISEA-1: The First C-Band SAR Miniaturized Satellite for Ocean and Coastal Observation
}

\author{
Sihan Xue ${ }^{1,2,3,+}$, Xupu Geng ${ }^{1,2,3,+} \mathbb{D}$, Lingsheng Meng ${ }^{1,3,4}$, Ting Xie ${ }^{1,2,3}$, Lei Huang ${ }^{4,5}$ and Xiao-Hai Yan $4,5, * \mathbb{D}$ \\ 1 State Key Laboratory of Marine Environmental Science, Xiamen University, Xiamen 361005, China; \\ xuesihan@stu.xmu.edu.cn (S.X.); gengxp@xmu.edu.cn (X.G.); lsmeng@udel.edu (L.M.); \\ xting@stu.xmu.edu.cn (T.X.) \\ 2 College of Ocean and Earth Sciences, Xiamen University, Xiamen 361005, China \\ 3 Fujian Engineering Research Center for Ocean Remote Sensing Big Data, Xiamen 361005, China \\ 4 College of Earth, Ocean and Environment, University of Delaware, Newark, DE 19716, USA; \\ lhuang@udel.edu \\ 5 Joint Institute for Coastal Research and Management (Joint-CRM), University of Delaware/Xiamen University, \\ Newark, DE 19716, USA \\ * Correspondence: xiaohai@udel.edu \\ + These authors contributed equally.
}

Citation: Xue, S.; Geng, X.; Meng, L.; Xie, T.; Huang, L.; Yan, X.-H. HISEA-1: The First C-Band SAR Miniaturized Satellite for Ocean and Coastal Observation. Remote Sens. 2021, 13, 2076. https://doi.org/ $10.3390 /$ rs13112076

Academic Editor:

Konstantinos Topouzelis

Received: 29 April 2021

Accepted: 23 May 2021

Published: 25 May 2021

Publisher's Note: MDPI stays neutral with regard to jurisdictional claims in published maps and institutional affiliations.

Copyright: (c) 2021 by the authors. Licensee MDPI, Basel, Switzerland. This article is an open access article distributed under the terms and conditions of the Creative Commons Attribution (CC BY) license (https:// creativecommons.org/licenses/by/ $4.0 /)$.

\begin{abstract}
On 22 December 2020, HISEA-1, the first C-band SAR small satellite for ocean remote sensing, was launched from the coastal Wenchang launch site. Though small in weight, the images it produced have a high spatial resolution of $1 \mathrm{~m}$ and a large observation width of $100 \mathrm{~km}$. The first batch of images obtained within the first week after the launch confirmed the rich information in the data, including sea ice, wind, wave, rip currents, vortexes, ships, and oil film on the sea, as well as landmark buildings. Furthermore, geometric characteristics of sea ice, wind vector, ocean wave parameter, 3D features of buildings, and some air-sea interface phenomena in dark spots could also be detected after relevant processing. All these indicate that HISEA-1 could be a reliable, remarkable, and powerful instrument for observing oceans and lands.
\end{abstract}

Keywords: HISEA-1; synthetic aperture radar (SAR); small satellite

\section{Introduction}

As small satellites and constellations develop rapidly, the new era of Synthetic Aperture Radar (SAR) satellites evolves. Using a low-cost and high-performance CubeSat and small satellite constellation, faster, more frequent, and more flexible data could be acquired. Using microwaves instead of light waves, the SAR signal is able to penetrate cloud and work at nighttime. The technology of pulse compression and synthetic aperture significantly improve the resolution of SAR images. As a result, two-dimensional (2D), all-weather, and all-day high-precision images could be obtained. Moreover, the C-band has been used comprehensively in ocean remote sensing, due to its phase that is convenient for ocean observations. There are many C-band sensors for ocean observation, such as Gaofen-3, Sentinel-1, and Radarsat-1/2, which can observe sea surface winds, sea ice, and ocean waves [1-11].

With the above background, the first C-band SAR ocean remote-sensing small satellite, named HISEA-1, was launched by the new Long March 8 medium-lift rocket from the coastal Wenchang launch site on 22 December 2020. With a weight of only $185 \mathrm{~kg}$, it can provide high-quality SAR remote-sensed images whose finest spatial resolution and maximum observation width reach $1 \mathrm{~m}$ and $100 \mathrm{~km}$, respectively. To introduce more concretely, the specifications of HISEA-1 are shown below.

First, the working orbit of HISEA-1 is a sun-synchronous circular orbit with a height of $512 \mathrm{~km}$ and an inclination of about $97^{\circ}$, and the mean local solar time is 12:00 (UTC $+8: 00)$. The shooting position can also be adjusted flexibly according to the mission; the 
global visiting rate may be up to $78.2 \%$ for three days, $95.5 \%$ for six days, and $99.78 \%$ for ten days. As an example, it observed 8 times within one month based on the simulation results. The attitude of the platform could also be adjusted accordingly, with the attitude control accuracy being $0.03^{\circ}$ and the attitude stability being $0.002 \%$ s. As C-band SAR, the center frequency of Hisea- 1 is $5.4 \mathrm{GHz}$, and the phased-array antenna has a size of $4.0 \mathrm{~m} \times 0.64 \mathrm{~m}$ (azimuth $\times$ range).

Second, the payload of HISEA-1 has three imaging modes: striping, spotlight, and scanning modes (Table 1). The incident angle is from $20^{\circ}$ to $35^{\circ}$ and the polarization is single VV (vertical transmit and vertical receive) polarization, which is vertical transmission and vertical reception. The spatial resolution and observation width are $3 \mathrm{~m}$ and $20 \mathrm{~km}$ respectively in striping mode, while the spatial resolution can reach as high as $1 \mathrm{~m}$ (azimuth) in spotlight mode. The spatial resolution and observation width of scanning mode are $10 \mathrm{~m}$ and $50 \mathrm{~km}$, or in wide mode, $20 \mathrm{~m}$ and $100 \mathrm{~km}$. As a comparison, Gaofen-3 SAR satellite has 12 image modes and more polarizations by virtue of the larger size (2750 kg to $180 \mathrm{~kg}$ ), while at a cost of much higher power ( $15 \mathrm{~kW}$ to $2.5 \mathrm{~kW}$ ) [4,9-12]. The small size and low power consumption largely lower the cost of each satellite, making it more suitable for a satellite constellation project, which is being planning and is just starting with HISEA-1.

Table 1. Main Parameters of HISEA-1.

\begin{tabular}{ccccc}
\hline Mode & Incident Angle $\left(^{\circ}\right)$ & Polarization & Resolution (m) & Width (km) \\
\hline Striping & $20-35$ & VV & 3 & 20 \\
Spotlight & $20-35$ & VV & up to 1 & $5 \times 5$ \\
(Azimuth) & 10 & 50 \\
$\begin{array}{c}\text { Scanning } \\
\text { Scanning } \\
\text { (Wide) }\end{array}$ & $20-35$ & VV & 20 & 100 \\
\hline
\end{tabular}

VV: vertical transmission and vertical reception.

The parameters of the platform and payload preliminarily exhibit the observation ability of HISEA-1 in terms of hardware. The first batch of high-definition (HD) images was received in the first week. External calibrations were made based on 13 Zhongwei Remote Sensing Satellite Calibration Field images (Ningxia, China); the geometric positioning, radiation accuracy and image quality of HISEA-1 were validated. The system sensitivity was tested through ten Amazon rainforest images. According to in-orbit tests, the peakto-sidelobe ratio (PRLR) is less than $27 \mathrm{~dB}$, the integrated sidelobe ratio (ISLR) is less than $-13 \mathrm{~dB}$, the azimuth ambiguity-to-signal ratio (AASR) is less than $-20 \mathrm{~dB}$, and the range-ambiguity-to-signal ratio (RASR) is less than $-20 \mathrm{~dB}$, while the Noise Equal Sigma Zero $\left(N E \sigma^{0}\right)$ is less than $-22 \mathrm{~dB}$ and the absolute radiometric accuracy is $2.0 \mathrm{~dB}(3 \sigma)$; all above satisfy the design requirements.

At this moment, the HISEA-1 satellite is still in the commissioning phase and the image processing plugin is also developing. When in the operation phase, a plugin based on SAR remote-sensing software, such as SNAP and ENVI-SARscape, will be provided. We are also developing our dataset system with official and detailed instructions of data availability; as a commercial satellite, we will also release some free SAR images to the public.

Based on the first batch of SAR images, we further analyzed and confirmed the powerful functions of these obtained SAR images. The results showed considerable information and landcover, including cities, mountains, farmlands, forests, rivers, lakes, glaciers, and coasts. Some typical data were initially analyzed in the next section.

\section{Typical Data and Preliminary Results}

\subsection{Sea Ice}

The sea ice image of the Bohai Sea in China was obtained from the striping imaging mode (Figure 1a). The shape and area of sea ice could be identified clearly. Considering some subsets of this image, the sea ice in different states could be observed. The backscatter is determined by many factors, including the dielectric properties of the constituents, the 
volume fraction of each constituent, the geometry (shape, size, and orientation) of brine pockets in ice, the surface conditions, as well as the property of snow cover $[13,14]$, which makes the sea ice show bright and dark values in the SAR images.

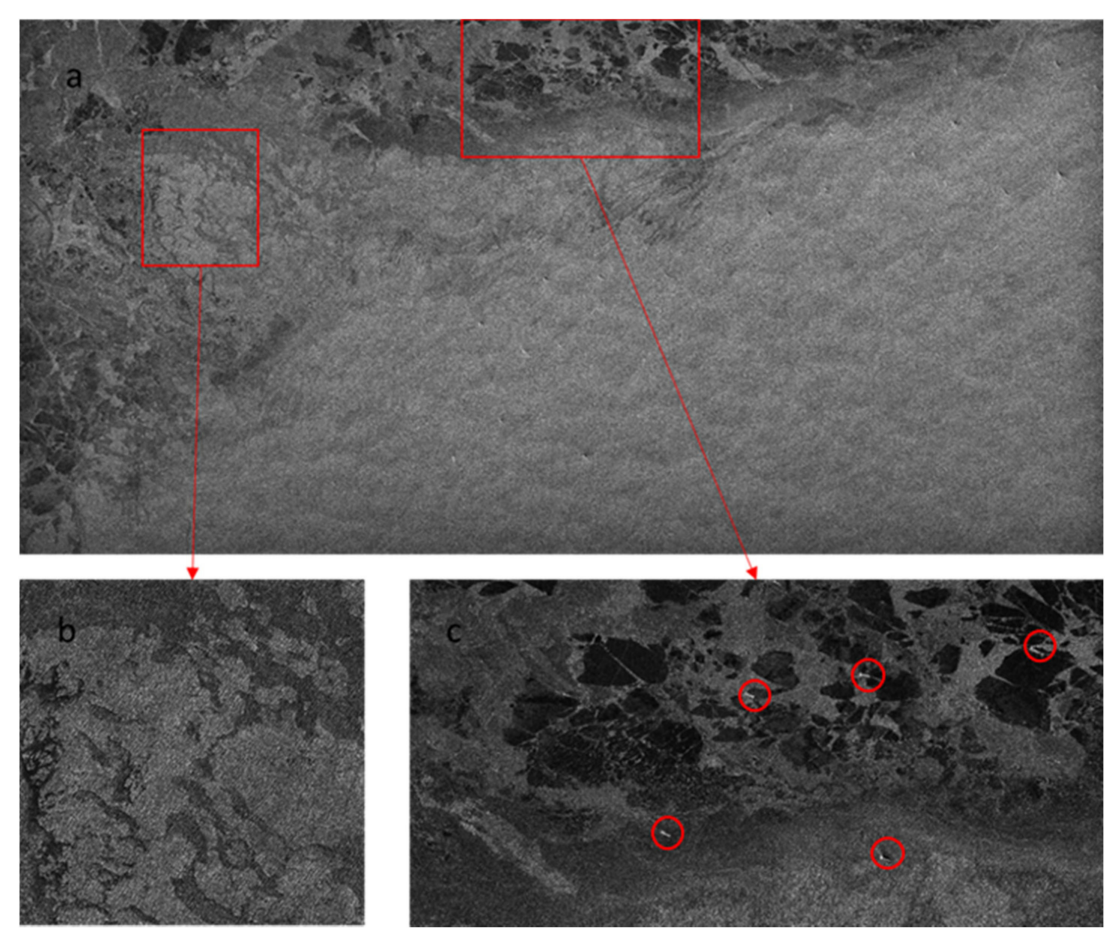

Figure 1. Sea ice image of the Bohai Sea in China obtained by HISEA-1 striping mode. (a) The complete obtained image whose gridding size is $31,764 \times 15,668$ (horizontal $\times$ vertical) and spatial resolution is $3 \mathrm{~m}$; (b) Sea ice with a brighter view; (c) Sea ice with a darker view. Red circles show ships trapped in the sea ice.

In Figure $1 b$, the bright area shows the distribution of the sea ice. This sea ice was rougher due to snowfall, and the edge of sea ice appears darker. The small striped bright pixels marked by red circles in Figure $1 \mathrm{~b}$ indicate the ships trapped in the sea ice. The sea ice in Figure 1c appears darker because the ice was smoother and younger and contained some leads. The leads were narrow irregular cracks consisting of thinner ice or open water, which are useful for the guidance of icebreaker routes.

Some interesting phenomena are also reflected in Figure $1 \mathrm{~b}$. There were a series of stripes extending from the sea surface to the sea ice. Those stripes that appear in the sea ice should be further investigated.

\subsection{Ocean Wind, Wave and Rip Current}

The image of South America is shown in Figure 2a. Various landcover, including buildings, farmlands, highways, rivers, and lakes, could be identified. At the same time, striped information is observed on the sea, which contains wind and wave information. Using the LG-mod [15], the wind direction was calculated, which contained $180^{\circ}$ blur. Figure 2c shows the SAR image spectra in the area marked by a red rectangle in Figure 2a. There is also a $180^{\circ}$ blur, and the wind direction is similar to that in Figure 2d. Based on the SAR image spectra, wave length and wave direction of the ocean wave could be obtained, for which the estimation of ocean wave spectra is a necessary prerequisite due to the nonlinear SAR-wave relation. There are several methods for ocean wave spectra inversion, including the Max-Planck Institute (MPI) method [16,17], the semi-parametric retrieval algorithm (SPRA) [18,19], the parameterized first-guess spectrum method (PFSM) [20], and the partition rescaling and shift algorithm (PARSA) [21,22]. In addition, the ocean wave parameters such as significant wave height, average wave period, and wave direction 
could also be estimated by the methods using the empirical relationship between wave parameters and SAR images, such as CWAVE [23-25], convolutional neural network (CNN) [26], and some empirical methods using azimuth cut-off, peak wavelength, and normalized variance to retrieve wave parameters [27]. These results suggest that HISEA-1 could observe winds and waves on sea surfaces. However, since the image was acquired under the commissioning stage, the image has not yet been calibrated. Therefore, the further works about ocean wave inversion would be done by the method mentioned above after testing step.
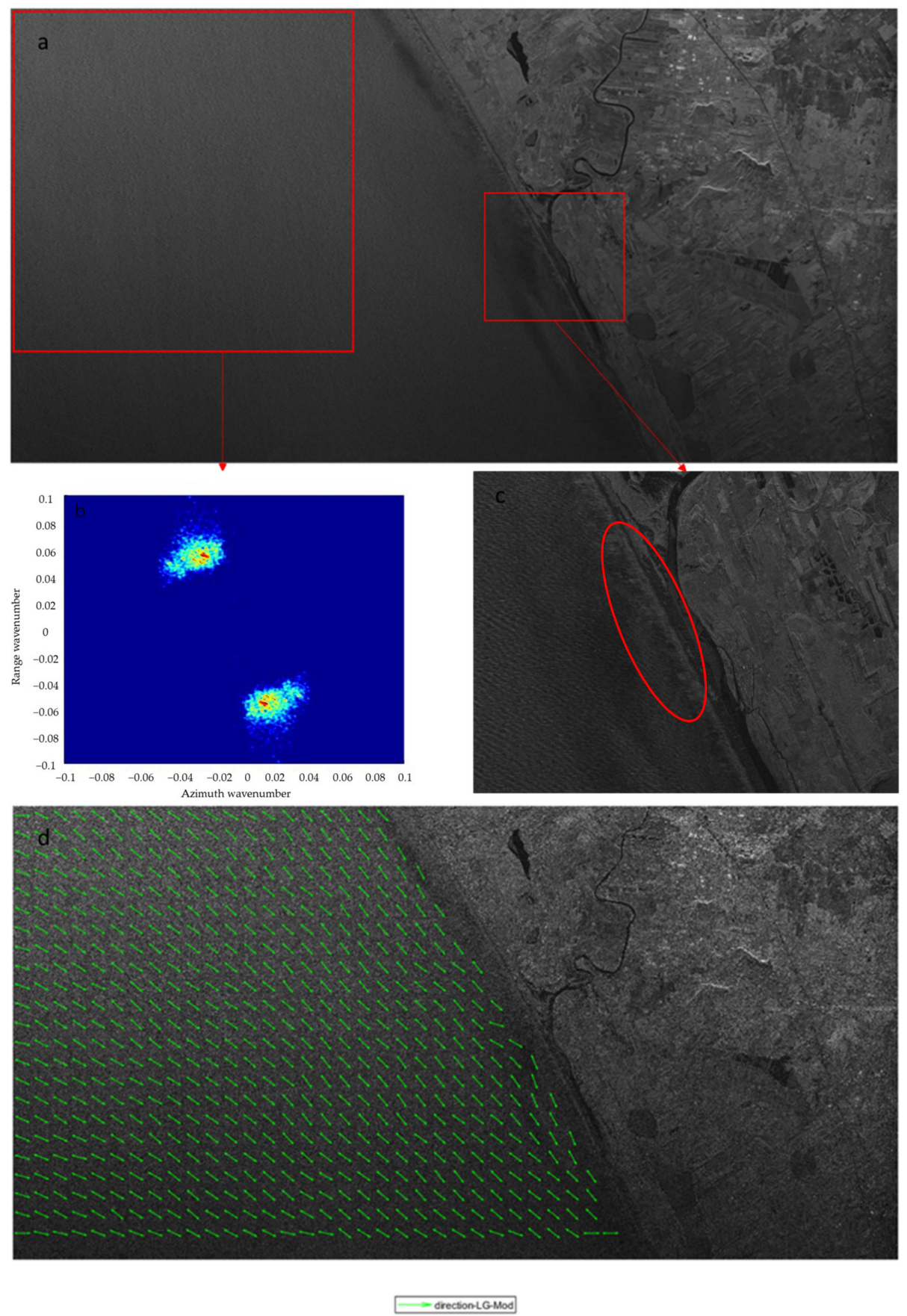

Figure 2. SAR image of North America obtained by striping mode and some preliminary analysis results. (a) Original SAR image whose gridding size is $14,000 \times 7167$ (horizontal $\times$ vertical) and spatial resolution is $3 \mathrm{~m}$. (b) SAR image spectra in the area enclosed by left red rectangle in Figure 2a. (c) Rip current in the right red rectangle in Figure 2a, which is shown in the red oval border. (d) Wind direction with $180^{\circ}$ blur retrieved by LG-mod. 
There are some other interesting phenomena in the coastal area. Some signatures of rip currents were identified in the central enlarged area along the coast in the SAR image, as shown in Figure 2c. Bright elongated cells extending offshore from the coast are inferred to be the rip currents [28]. In addition, there are some irregular bright bands in the sand bar, which could be further analyzed by geologists.

\subsection{D Features of High Rise}

The area in the red rectangle on the right of Figure 3 is the Siming Campus of Xiamen University. Buildings, lakes, and playgrounds are also shown in the image. Twin towers are observed at the lower-right corner of the right rectangle. The 3D features of some high-rises were shown in the red ovals, in which the bottom is dark and top is bright. Based on the phase information, the quantitative geometric features could be obtained further.

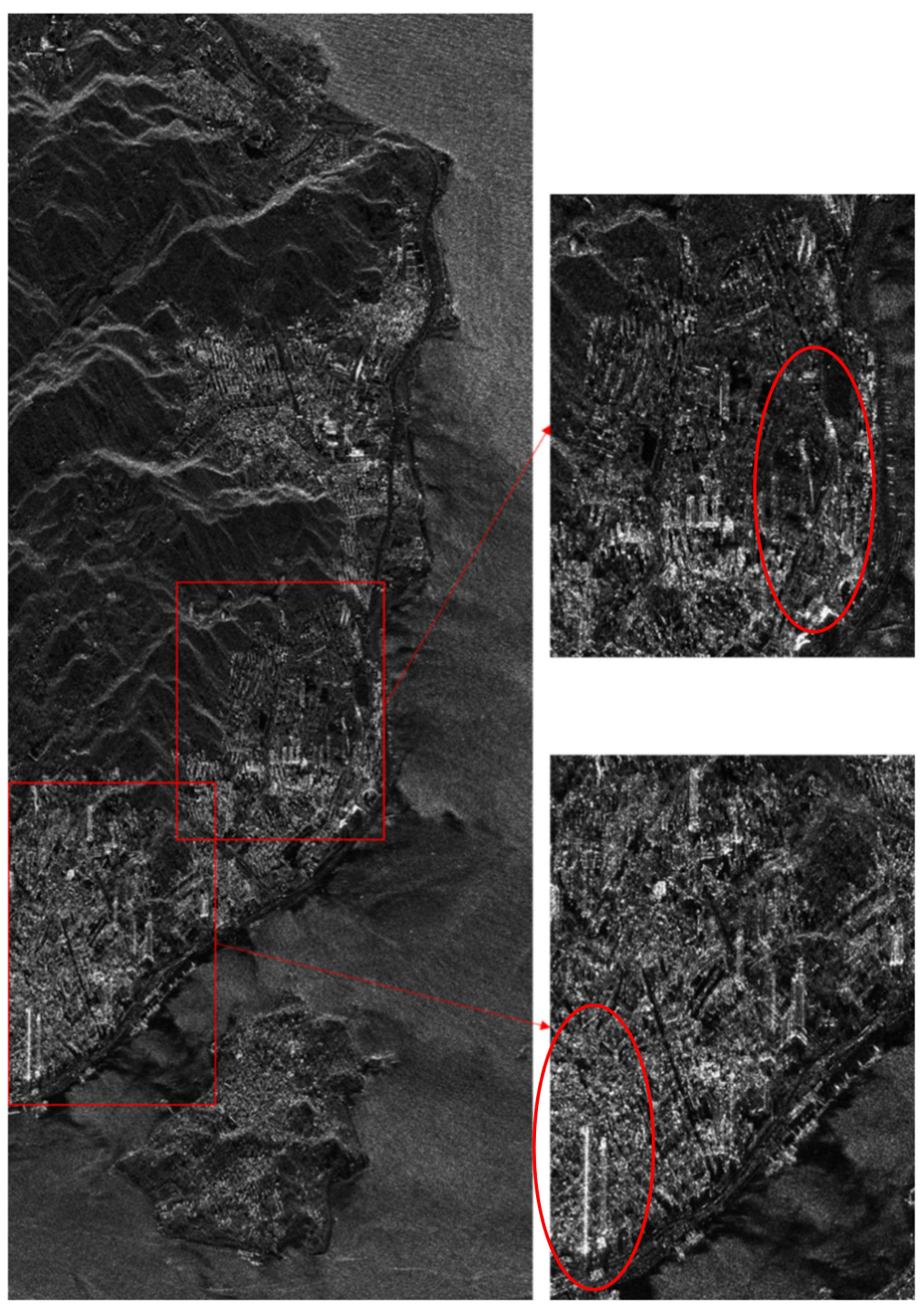

Figure 3. One-meter resolution spotlight-mode SAR image of Xiamen University Siming Campus, the gridding size is $1937 \times 4750$ (horizontal $\times$ vertical). The left red rectangle border indicates the high-rise area, which shows some $3 \mathrm{D}$ features of buildings. The right red rectangle indicates the main part of the campus. The oval borders indicate the high rises' location.

\subsection{Dark Spots in Image of Kerch Strait}

Kerch Strait is located in the Black Sea. The surface salinity of the Black Sea is low because of the freshwater injection from rivers and low-salinity water injection from the surface of the Mediterranean Sea. However, high-salinity water flows deep into the Black 
Sea from the Mediterranean Sea. Therefore, there is nearly no interaction between deep and shallow waters [29]. The Azov Sea is the shallowest in the world. Kerch Strait is an important waterway between the Black Sea and Azov Sea [30].

Figure 4 shows the striping-mode SAR image of the Kerch Strait. Different cultivated lands appeared as regular squares. The Kerch Strait Bridge spans the strait, and many ships and their wakes are shown in the image. The dark spots in the sea may be oil slicks, upwelling, rain cells, or low-wind-speed areas. The oil film also makes it convenient to study some marine phenomena such as vortexes [31]. Note that the dark spots in Figure 4 were located in the coastal area, so the spots show the polluted domestic water discharged into the ocean. The shape features of dark spots also reveal the current direction. As a result, some features of the air-sea interface phenomena in those dark spots areas could be more easily observed by SAR. The strips of the dark spot at the lower-left corner of the image were the wind streaks. The current under the Kerch Strait Bridge appeared as regular strips, and some vortex structures were also found at the bottom of the image.
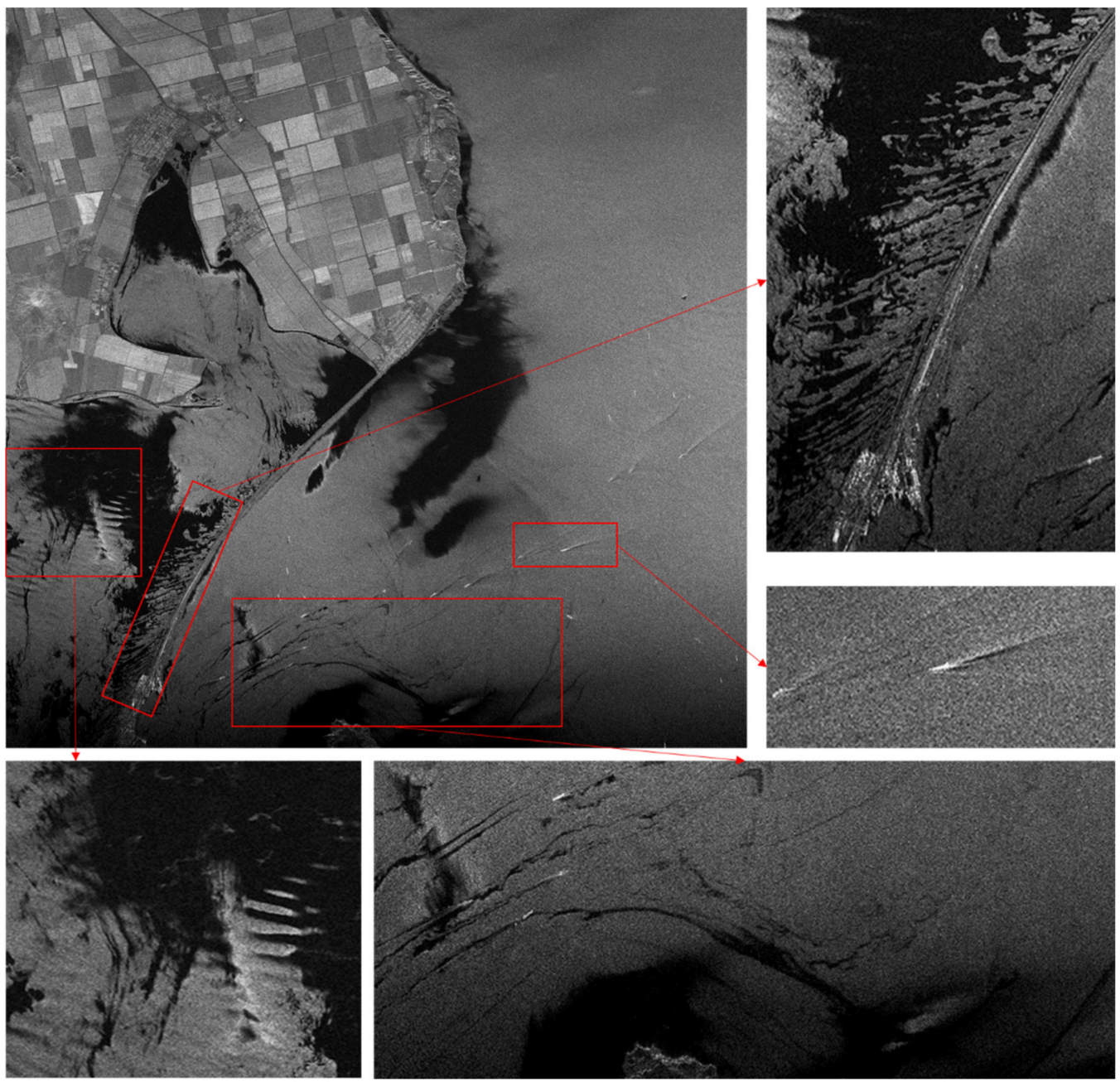

Figure 4. Three-meter resolution striping-mode SAR image of the Kerch Strait; the gridding size is $2000 \times 2000$ (horizontal $\times$ vertical).

\subsection{Coastal Observation in Delaware Bay}

An image of Delaware Bay is shown in Figure 5, which also contains the information of ocean and coastal observations. Figure $5 \mathrm{a}$ is the whole image, in which the stripe information of wind and wave, rivers, and ships could be recognized clearly. Wind and wave are important phenomena which could provide reference for human activities, and 
retrieve underwater terrain. The images in the red rectangles show more specific details. In Figure $5 b$, the freshwater rivers are shown as a dark color because the salinity of freshwater is lower than seawater. HISEA-1 could also be used to retrieve the areas with terrestrial freshwater bodies, and the shape of freshwater plumes could be found in the coastal estuaries which are marked with red circles in Figure 5b. In Figure 5c, the bright spots are the sailing ships whose wakes are clearly visible. The ship identification and the ship wakes play important roles in maritime and navigation management. In Figure $5 \mathrm{~d}$, several strip-shaped buildings in the sea could be recognized clearly, which are embankments or piers. The red circles and ovals mark the area of University of Delaware Lewes campus, fishing pier Cape Henloppen, Cape Henlopen State Park and University of Delaware Air Sea Interaction Lab, and Cape Henlopen, shown in the order from left to right. In addition, some dark spots appear in the coastal region, which represent the discharge of sewage.
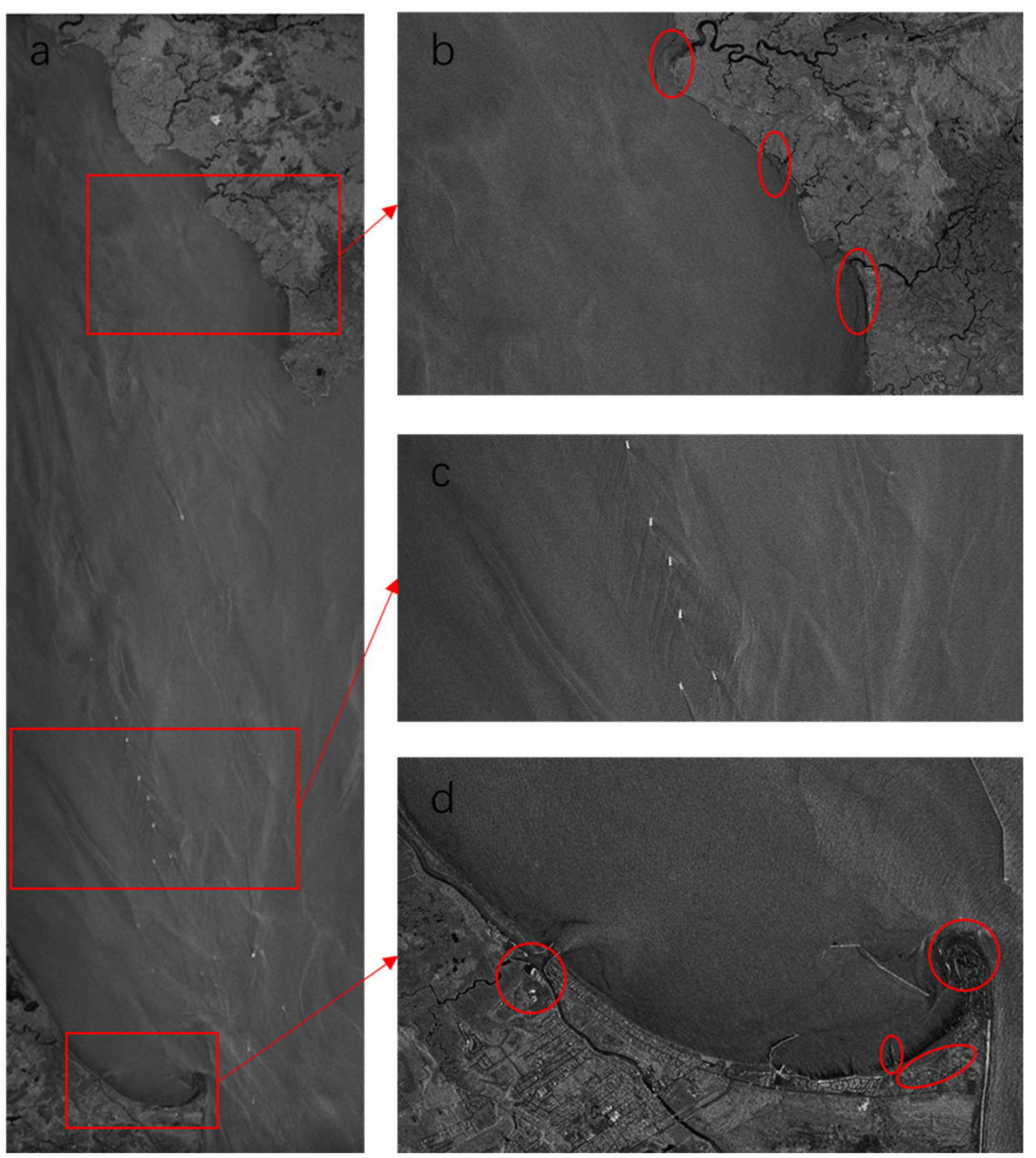

Figure 5. Image of Delaware Bay obtained by striping mode. (a) Whole SAR image of Delaware Bay whose gridding size is $13,996 \times 44,480$ (horizontal $\times$ vertical) and spatial resolution is $3 \mathrm{~m}$. (b) Enlarged view in the top rectangle area in Figure 1a as the arrow points. (c) Enlarged view in the middle rectangle area in Figure 1a as the arrow points. (d) Enlarged view in the bottom rectangle area in Figure 1a as the arrow points.

\section{Conclusions}

As the first C-band SAR ocean remote-sensing small satellite, HISEA-1 can obtain images with a spatial resolution of up to $1 \mathrm{~m}$ and a large imaging width of $100 \mathrm{~km}$. The 
first batch of images from HISEA-1 provided considerable information about the land and seas. Images of land could identify different landcover, including buildings, arable lands, highways, rivers, and lakes. It could also provide 3D features of high rises. On the sea, sea ice, some vortex phenomena, oil film, rip currents, etc., could be identified in the images. Some wind and wave parameters could also be retrieved from the SAR images of the ocean.

This paper has confirmed the great potential of HISEA-1 in ocean and coastal observations. Given the relatively low weight and cost, it is more convenient to construct the satellite constellation with more small satellites such as this, which is what we are planning and will be carried out in the foreseeable future. However, HISEA-1 is still in the commissioning stage and the calibration has not yet been finally finished; more relevant analysis and products will be generated as the calibration and track data are completed.

Author Contributions: Conceptualization, X.G. and S.X.; writing—original draft preparation, S.X.; writing-review and editing, X.G., L.M., X.-H.Y. and L.H.; visualization, S.X. and T.X. All authors have read and agreed to the published version of the manuscript.

Funding: This research was funded by the National Key R\&D Program of China (2019YFA0606702), the SOA Global Change and Air-Sea Interaction Project (grant numbers GASI-02-PAC-YGST2-02) and the National Natural Science Foundation of China (grant numbers 41630963, 41776003 and 91858202).

Institutional Review Board Statement: Not applicable.

Informed Consent Statement: Not applicable.

Data Availability Statement: The data presented in this study are available on request from the corresponding author. The data are not publicly available because HISEA-1 is still in commissioning stage.

Acknowledgments: The authors would like to thank Spacety and China Electronics Technology Group Corporation (CETC) 38th Institute for developing satellite platform and SAR payload, and thank all participants and collaborators involved in the HISEA-1 C-band SAR small satellite project.

Conflicts of Interest: The authors declare no conflict of interest.

\section{References}

1. He, Y.; Zhang, B.; Perrie, W. Validation of RADARSAT-2 Polarimetric SAR Measurements of Ocean Waves. In Proceedings of the 2010 IEEE Geoscience and Remote Sensing Symposium (IGARSS), Honolulu, HI, USA, 25-30 July 2010.

2. Hui, S.; Perrie, W.; He, Y.; Liu, G. Wind speed retrieval from VH dual-polarization radarsat-2 SAR images. IEEE Trans. Geosci. Remote Sens. 2014, 52, 5820-5826.

3. Li, X.; Jackson, C.; Monaldo, F.; Xu, Q.; Bao, S. Application Sentinel-1 SAR Data for Ocean Research and Operation. In Proceedings of the 2016 IEEE International Geoscience and Remote Sensing Symposium (IGARSS), Beijing, China, 10-15 July 2016.

4. Li, X.-M.; Zhang, T.; Huang, B.; Jia, T. Capabilities of Chinese Gaofen-3 Synthetic Aperture Radar in Selected Topics for Coastal and Ocean Observations. Remote Sens. 2018, 10, 1929. [CrossRef]

5. Li, X.M.; Sun, Y.; Zhang, Q. Extraction of sea ice cover by Sentinel-1 SAR based on support vector machine with unsupervised generation of training data. IEEE Trans. Geosci. Remote Sens. 2020, 99, 1-14.

6. Lin, B.; Shao, W.; Li, X.; Li, H.; Du, X.; Ji, Q.; Cai, L. Development and validation of an ocean wave retrieval algorithm for VV-polarization Sentinel-1 SAR data. Acta Oceanol. Sin. 2017, 36, 95-101. [CrossRef]

7. Song, D.; Ding, Y.; Li, X.; Zhang, B.; Xu, M. Ocean oil spill classification with Radarsat-2 SAR based on an optimized wavelet neural network. Remote Sens. 2017, 9, 799. [CrossRef]

8. Topouzelis, K.; Singha, S. Oil spill detection using space-borne Sentinel-1 SAR imagery. In Oil Spill Science and Technology, 2nd ed.; Fingas, M., Ed.; Spill Science: Edmonton, AB, Canada, 2017; pp. 387-402.

9. Wang, H.; Yang, J.; Mouche, A.; Shao, W.; Zhu, J.; Ren, L.; Xie, C. GF-3 SAR Ocean Wind Retrieval: The First View and Preliminary Assessment. Remote Sens. 2017, 9, 694. [CrossRef]

10. Wang, H.; Wang, J.; Yang, J.; Ren, L.; Zhu, J.; Yuan, X.; Xie, C. Empirical Algorithm for Significant Wave Height Retrieval from Wave Mode Data Provided by the Chinese Satellite Gaofen-3. Remote Sens. 2018, 10, 363. [CrossRef]

11. Yang, J.; Wang, J.; Ren, L. The first quantitative remote sensing of ocean internal waves by Chinese GF-3 SAR satellite. Acta Oceanol. Sin. 2017, 36, 118. [CrossRef]

12. Sun, J.; Yu, W.; Deng, Y. The SAR payload design and performance for the GF-3 mission. Sensors 2017, 17, 2419. [CrossRef] [PubMed]

13. Shuchman, R.A.; Flett, D.G. SAR Measurement of Sea Ice Parameters: Sea Ice Session Overview Paper. In Proceedings of the Second Workshop on Coastal and Marine Applications of SAR, Svalbard, Norway, 8-12 September 2003; European Space Agency: Noordwijk, The Netherlands, 2004; pp. 151-160. 
14. Yu, Q. Automated SAR Sea Ice Interpretation. Ph.D. Thesis, Department of Systems Design Engineering, University of Waterloo, Waterloo, ON, Canada, 2006.

15. Rana, F.M.; Maria, A.; Guido, P.; Giacomo, D.C.; Sandra, M. Lg-mod: A modified local gradient (lg) method to retrieve SAR sea surface wind directions in marine coastal areas. J. Sens. 2016, 2016, 9565208. [CrossRef]

16. Hasselmann, K.; Hasselmann, S. On the nonlinear mapping of an ocean wave spectrum into a synthetic aperture radar image spectrum. J. Geophys. Res. 1991, 96, 10713-10729. [CrossRef]

17. Hasselmann, S.; Bruning, C.; Hasselmann, K. An improved algorithm for the retrieval of ocean wave spectra from synthetic aperture radar image spectra. J. Geophys. Res. 1996, 101, 16615-16629. [CrossRef]

18. Mastenbroek, C.; De Valk, C.F. A semi-parametric algorithm to retrieve ocean wave spectra from synthetic aperture radar. J. Geophys. Res. 2000, 105, 3497-3516. [CrossRef]

19. Zhang, B.; Li, X.F.; Perrie, W.; He, Y.J. Synergistic measurements of ocean winds and waves from SAR. J. Geophys. Res. 2015, 120, 6164-6184. [CrossRef]

20. Sun, J.; Guan, C.L. Parameterized first-guess spectrum method for retrieving directional spectrum of swell-dominated waves and huge waves from SAR images. Chin. J. Oceanol. Limnol. 2006, 24, 12-20.

21. Schulz-Stellenfleth, J.; Lehner, S.; Hoja, D. A parametric scheme for the retrieval of two-dimensional ocean wave spectra from synthetic aperture radar look cross spectra. J. Geophys. Res. 2005, 110, 297-314. [CrossRef]

22. Li, X.M.; Konig, T.; Schulz-Stellenfleth, J.; Lehner, S. Validation and intercomparison of ocean wave spectra inversion schemes using ASAR wave mode data. Int. J. Remote Sens. 2010, 31, 4969-4993. [CrossRef]

23. Li, X.M.; Lehner, S.; Bruns, T. Ocean wave integral parameter measurements using Envisat ASAR wave mode data. IEEE Trans. Geosci. Remote. Sens. 2011, 49, 155-174. [CrossRef]

24. Schulz-Stellenfleth, J.; Konig, T.; Lehner, S. An empirical approach for the retrieval of integral ocean wave parameters from synthetic aperture radar data. J. Geophys. Res. 2007, 112, C03019. [CrossRef]

25. Stopa, J.E.; Mouche, A. Significant wave heights from Sentinel-1 SAR: Validation and applications. J. Geophys. Res. Ocean. 2017, 122, 1827-1848. [CrossRef]

26. Xue, S.; Geng, X.; Yan, X.H.; Xie, T.; Yu, Q. Significant wave height retrieval from Sentinel-1 SAR imagery by convolutional neural network. J. Oceanogr. 2020, 76, 465-477. [CrossRef]

27. Shao, W.; Zhang, Z.; Li, X.F.; Li, H. Ocean wave parameters retrieval from Sentinel-1 SAR imagery. Remote Sens. 2016,8 , 707. [CrossRef]

28. Silva, J.C.B.D. SAR Observation of Rip Currents off the Portuguese Coast. In Remote Sensing of the European Seas, 1st ed.; Barale, V., Gade, M., Eds.; Springer: Dordrecht, The Netherlands, 2008; pp. 399-410.

29. Stanev, E.V.; Peneva, E.; Chtirkova, B. Climate Change and Regional Ocean Water Mass Disappearance: Case of the Black Sea. J. Geophys. Res. Ocean. 2019, 124, 4803-4819. [CrossRef]

30. Mizyuk, A.I.; Lishaev, P.N.; Puzina, O.S. Estimation of the Azov Sea state based on the Black Sea hydrography. J. Phys. Conf. Ser. 2020, 1675, 012120. [CrossRef]

31. Lavrova, O.Y.; Bucharova, T.Y.; Mityagina, M.I. SAR Observations of Typical Phenomena in the Black Sea Shore Area. In Proceedings of the 2003 IEEE Geoscience and Remote Sensing Symposium (IGARSS), Toulouse, France, 21-25 July 2003. 